\title{
Origen coronario anómalo combinado con válvula aórtica bicúspide
}

\section{Anomalous coronary origin combined with bicuspid aortic valve}

\section{Ricardo Levin*}

Departamento de Cardiología y Cirugía Cardiovascular, Hospital Universitario, Universidad Abierta Interamericana (UAl), Buenos Aires, Argentina

Se presenta el caso de un varón de 58 años con estenosis aórtica grave y válvula bicúspide, remitido para sustitución valvular. Como parte de su evaluación prequirúrgica se realizó una cinecoronariografía que reveló un origen anómalo de la arteria descendente anterior, la cual nace desde el seno coronario derecho, junto a

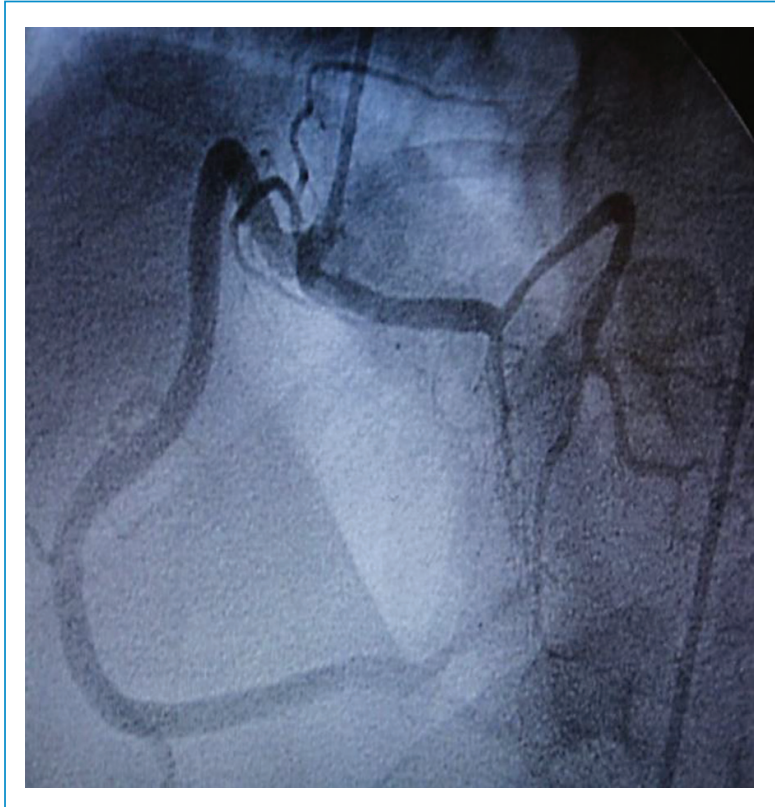

Figura 1. Cinecoronariografia dónde se observa el origen anómalo de la arteria descendente anterior desde el seno derecho. la coronaria homónima (Fig. 1). Ante este hallazgo se solicitó una angiotomografía coronaria para definir el trayecto del vaso, precisándose el origen común de las arterias descendente anterior y coronaria derecha. La primera tenía un curso entre la raíz aórtica y la arteria pulmonar, y su recorrido subpulmonar, ingresando posteriormente en el tabique interventricular (tercio superior) a través de un curso transeptal. Así mismo, se observó el origen de la arteria circunfleja desde el mismo seno coronario, pero con un ostium independiente

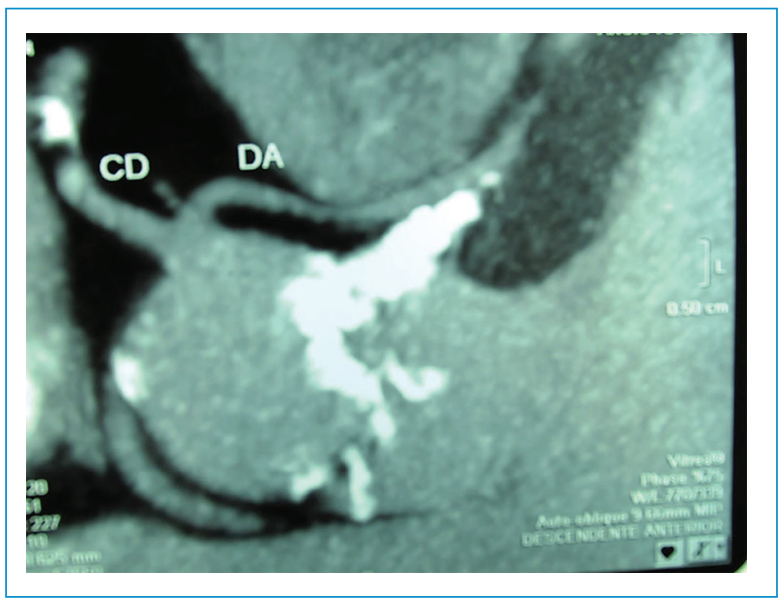

Figura 2. Angiotomografia coronaria en la cual resulta evidente el origen conjunto de la descendente anterior y coronaria derecha desde el seno de valsalva derecho. CD: coronaria derecha; DA: descendente anterior.

\section{Correspondencia:}

${ }^{*}$ Ricardo Levin

E-mail: rllevin@gmail.com
Fecha de recepción: 20-07-2019

Fecha de aceptación: 19-08-2020 DOI: 10.24875/RCCAR.M21000072
Disponible en internet: $18-10-2021$ Rev Colomb Cardiol. 2021;28(4):397-398 www.rccardiologia.com 0120-5633 / @ 2021 Sociedad Colombiana de Cardiología y Cirugía Cardiovascular. Publicado por Permanyer. Este es un artículo open access bajo la licencia CC BY-NC-ND (http://creativecommons.org/licenses/by-nc-nd/4.0/). 


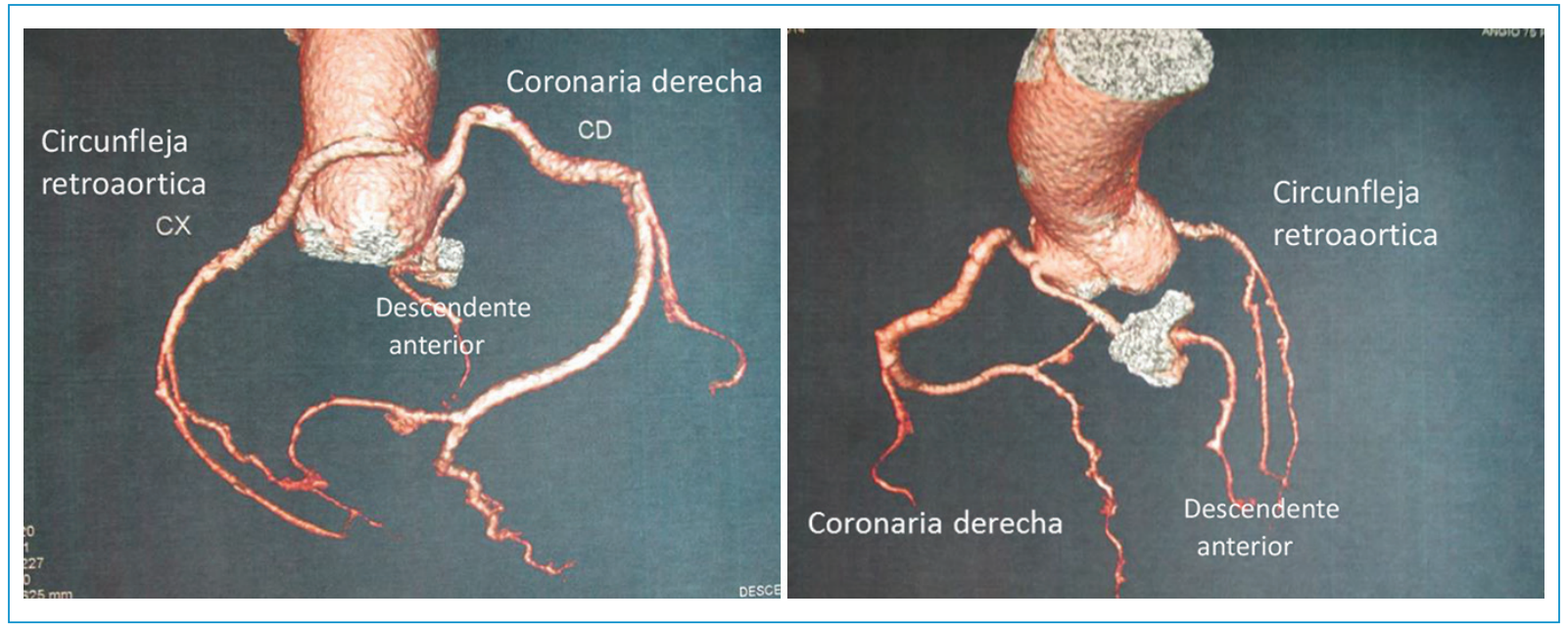

Figura 3. Imagen de reconstrucción tridimensional de la angiotomografia coronaria en la que se aprecia el origen conjunto de la coronaria derecha y descendente anterior, un origen aislado de la circunfleja desde el seno izquierdo con un trayecto retro-aórtico y la existencia de dos cúspides aórticas.

y un trayecto retroaórtico (Figs. 2-3). El origen anómalo de la arteria coronaria izquierda en el seno de Valsalva derecho tiene una prevalencia del $0,02-0,03 \%$, resulta infrecuente su asociación con válvula aórtica bicúspide y existen pocos casos reportados. Como particularidad agregada, todas las arterias coronarias se originan en el mismo seno de Valsalva. Al paciente se le practicó reemplazo valvular con prótesis mecánica y baipás mamario a la descendente anterior. La evolución posoperatoria resultó libre de eventos.

\section{Conflicto de intereses}

El autor declara que no existe conflicto de intereses.

\section{Responsabilidades éticas}

Protección de personas y animales. Los autores declaran que para esta investigación no se han realizado experimentos en seres humanos ni en animales.

Confidencialidad de los datos. Los autores declaran que en este artículo no aparecen datos de pacientes.

Derecho a la privacidad y consentimiento informado. Los autores han obtenido el consentimiento informado de los pacientes y/o sujetos referidos en el artículo. Este documento obra en poder del autor de correspondencia. 